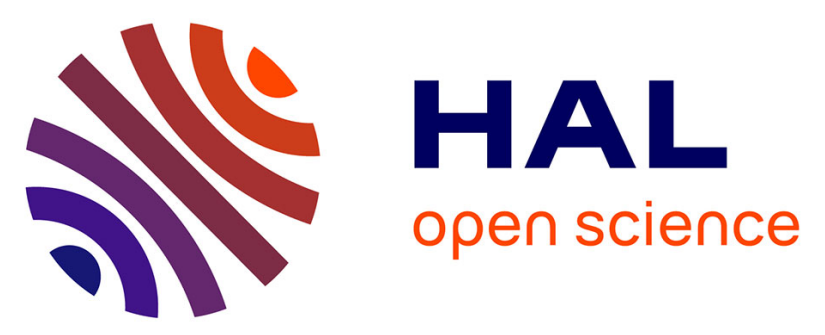

\title{
ANALYSIS OF CRACKING DUE TO SHRINKAGE RESTRAINT ON THE MECHANICAL BEHAVIOUR OF REINFORCED CONCRETE
}

\author{
A. Michou, A. Hilaire, F. Benboudjema, G Nahas, P Wyniecki, Y. Berthaud
}

\section{To cite this version:}

A. Michou, A. Hilaire, F. Benboudjema, G Nahas, P Wyniecki, et al.. ANALYSIS OF CRACKING DUE TO SHRINKAGE RESTRAINT ON THE MECHANICAL BEHAVIOUR OF REINFORCED CONCRETE. 9th International Conference on Fracture Mechanics of Concrete and Concrete Structures, May 2016, San Francisco, United States. hal-01706636

\section{HAL Id: hal-01706636 \\ https://hal.science/hal-01706636}

Submitted on 12 Feb 2018

HAL is a multi-disciplinary open access archive for the deposit and dissemination of scientific research documents, whether they are published or not. The documents may come from teaching and research institutions in France or abroad, or from public or private research centers.
L'archive ouverte pluridisciplinaire HAL, est destinée au dépôt et à la diffusion de documents scientifiques de niveau recherche, publiés ou non, émanant des établissements d'enseignement et de recherche français ou étrangers, des laboratoires publics ou privés. 


\title{
ANALYSIS OF CRACKING DUE TO SHRINKAGE RESTRAINT ON THE MECHANICAL BEHAVIOUR OF REINFORCED CONCRETE
}

\author{
A. MICHOU $^{\dagger}$, A. HILAIRE ${ }^{*}$, F. BENBOUDJEMA ${ }^{*}$, G. NAHAS ${ }^{\dagger \dagger}$, P. WYNIECKI $^{\dagger}$ AND Y. \\ BERTHAUD \\ LMT (ENS Cachan, CNRS, Université Paris Saclay) \\ Cachan, France \\ e-mail: farid.benboudjema@ens-cachan.fr, adrien.hilaire@epfl.ch \\ Nuvia Structure \\ Aix-en-Provence, France \\ e-mail: alexandre.michou@nuvia.fr, pierre.wyniecki@nuvia.fr \\ ${ }^{\dagger \dagger}$ Institut de Radioprotection et de Sûreté Nucléaire \\ Fontenay-aux-Roses, France \\ e-mail: georges.nahas@irsn.fr \\ Sorbonne Universités, UPMC Univ Paris 06, CNRS, Institut Jean le Rond d'Alembert \\ Paris, France \\ e-mail: yves.berthaud@upmc.fr
}

Key words: shrinkage, creep, cracking, prestress, reinforcement, bond

Abstract: Shrinkage may lead to tensile stresses and cracking in reinforced concrete structures due to several mechanisms: gradients of drying shrinkage, restraint of autogeneous and drying shrinkage by reinforcement or concrete members of different thickness or ages etc. This contribution focuses on the effect of drying shrinkage on the behavior of concrete tie members, with a focus on the restraint by reinforcement. It is showed that, if it is not taken into account, numerical simulations show an overestimation of cracking and force at first crack when submitted to uniaxial tension when compared to experimental results. Besides, an appropriate interface model should be also introduced in order to be relevant.

\section{INTRODUCTION}

Delayed strains (shrinkage and creep) of concrete can be of crucial importance for the assessment of the behavior of concrete structure. In partially prestressed concrete structures, they participate to the prestress loss. If shrinkage strains are restraint, tensile stresses appear and can lead to cracking. The restraint may be "intern", i.e. due to gradients of temperature/relative humidity or "extern", i.e., due to the previous casting of structural member, like raft foundations, in the case of concrete lift etc. A lot of studies in the literature deal with these issues [1,2].

However, in reinforced concrete structures, shrinkage restraint by steel rebars, in a similar way that shrinkage of cement paste is restrained by aggregates, has not been deeply investigated. It induces a self-equilibrated state of stress: tensile stresses in concrete and compressive stresses in steel rebars in the case of uniform shrinkage (as for autogeneous 
shrinkage). It may lead to cracking of concrete, partial debonding at the steel/concrete interface, or just initial tensile stresses in concrete around the rebar. In any case, it should affect the behavior of reinforced concrete structures, especially in structures submitted to tension or in bending: loss of stiffness and bearing capacity. Besides, since drying is not uniform, gradient of drying shrinkage induces tensile stresses at the surface equilibrated by compressive stresses in the core. The prediction of this initial state of stress needs the characterization of drying, shrinkage, creep, elastic and fracture properties.

In order to investigate the effect of shrinkage restraint, an extensive experimental program has been carried out: pull-out tests, reinforced concrete ties in tension, as well as shrinkage and creep tests. In addition, numerical simulations have been undertaken in order to assess the residual properties in tension and bending: rigidity, bearing capacity and crack openings (assessed by Digital Image Correlation) [3]. The numerical simulations in concrete ties show that, without taking into account shrinkage restraint, the stiffness and the force corresponding to the onset of cracking are overestimated. However, when drying shrinkage is taken into account without the effect of basic and drying creep, an opposite result is obtained. Therefore, shrinkage and creep should be taken into account in the analysis. Indeed, tensile stresses of a few MPa are found in the concrete around the rebars and superficial cracking are predicted in concrete ties, which reduce the bearing capacity of concrete.

\section{EXPERIMENTAL CAMPAIGN}

Each specimen is fabricated with the same concrete mixture and the same steel rebar, in order to limit the variability of both the material and the bond properties. The samples are protected against desiccation up to 17 days and are tested after 110 days. They are therefore exposed to drying conditions during 90 days (average relative humidity of $40 \%$ ). Concrete mixture presents a water-cement ratio equal to 0.48 . Concrete properties are measured on cylindrical samples: Young's modulus, tensile strength (splitting test) and compressive strength $E_{c} ; f_{t}$ and $f_{c}$, respectively) and on notched concrete beams (fracture energy $G_{f}$ ) [4]. The results are presented in Table 1, as well as the mechanical properties of the steel rebar: Young's modulus $E_{s}$, yield strength $f_{y}$.

The specimens are protected against desiccation up to 17 days and are tested 110 days after pouring. They are exposed to an average relative humidity of $40 \%$ and an average temperature of $22{ }^{\circ} \mathrm{C}$. Specific attention is also devoted to the "life" of the specimen before mechanical loading. Therefore, phenomena such as autogenous shrinkage, drying shrinkage, creep, are also studied. Indeed, they induce a self-equilibrated stress field in the structure. Since the delayed strains are restrained by the steel rebars, tensile stresses are induced in concrete, which may lead to a debonding at the steel-concrete interface, the same way as the cracking and debonding at the aggregates-cement paste interface [2].

Table 1: Properties of concrete and steel

\begin{tabular}{cccc}
\hline Concrete & $\begin{array}{c}\text { Mean } \\
\text { value }\end{array}$ & $\begin{array}{c}\text { Steel } \\
\text { bar }\end{array}$ & \\
\hline $\mathrm{Ec}$ & $35 \mathrm{GPa}$ & $E_{s}$ & $200 \mathrm{GPa}$ \\
\hline$f_{t}$ & $2.9 \mathrm{MPa}$ & $f_{y}$ & $500 \mathrm{MPa}$ \\
\hline$f_{c}$ & $49.4 \mathrm{MPa}$ & & \\
\hline$G_{f}$ & $94.6 \mathrm{~J} / \mathrm{m}^{2}$ & & \\
\hline
\end{tabular}

\subsection{Experimental bond tests}

Standard pull-out tests have been carried out. A single rebar of diameter $d=12 \mathrm{~mm}$ is embedded into a $15 d$ concrete cube. The anchorage length is equal to $5 d$ (Fig. 1b). This configuration provides a mechanism of pulling, instead of splitting. Teflon sheets are added on the loaded surface, as detailed in Fig. 1a, in order to avoid friction and spurious stresses in the specimen. The connection between the specimen and the fixed support is managed by a steel bearing (Fig. 1c). A displacement sensor is located at the unloading 
end of the rebar, measuring its relative slip with concrete. The bond stress $\tau$ (if it is supposed to be constant along the anchorage length $l$ ), can be deduced from the applied load $F$ :

$$
\tau=\frac{F}{\pi d l}
$$

\subsection{Experimental tension tests on reinforced concrete ties}

Tests on long reinforced concrete ties are then carried out (Fig. 2). Three 1.15 m-long structures are tested in tension. The concrete cross section is equal to $10 \times 10 \mathrm{~cm}^{2}$. The length of the specimens favors the localization of multiple transverse cracks during loading. A steel rebar (identical to the rebar in pull-out bond tests, diameter $d=12 \mathrm{~mm}$ ) is embedded on $1 \mathrm{~m}$. The test is performed up to yielding of reinforcement.

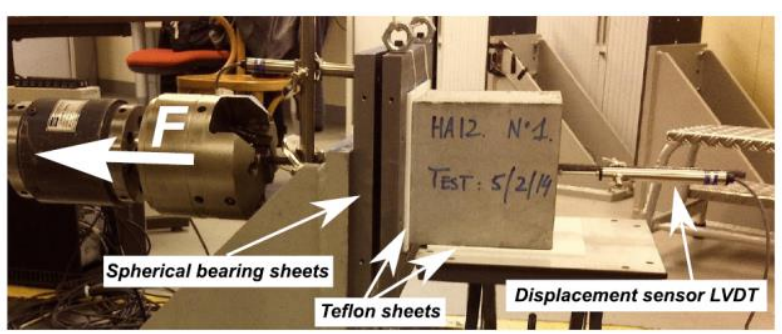

(a)

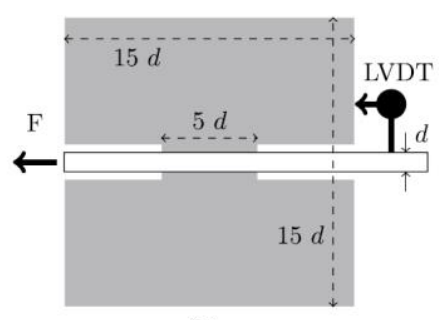

(b)

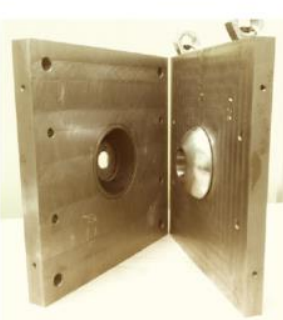

(c)
Figure 1: Configuration of the pull-out tests: (a) tested specimens, (b) geometrical dimensions, and (c) steel bearing for axiality.

Digital Image Correlation [3], noted DIC, is performed during loading on each specimen but on one side only.

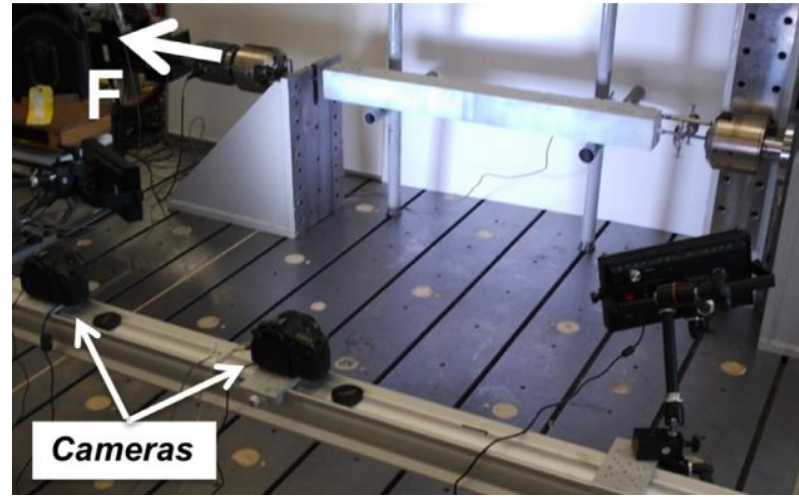

Figure 2: RC tie in tension: experimental set up.

The final cracking patterns are presented in Fig. 3, after yielding of reinforcement. Five or six cracks localize during loading, perpendicular to the loading axis. These qualitative results can then serve as a comparison with the numerical simulations. A quantitative characterization of the cracking behavior can also be proposed. First, the sum of crack openings $S_{o p}$ is defined as:

$$
S_{o p}=\sum_{i} w_{i}
$$

where $w_{i}$ is the crack opening of crack $i$. This criterion is related to the elongation of the specimens. It can be also presented as a durability criterion. A flow by diffusion across a structure is linear with respect to the crack opening [5].
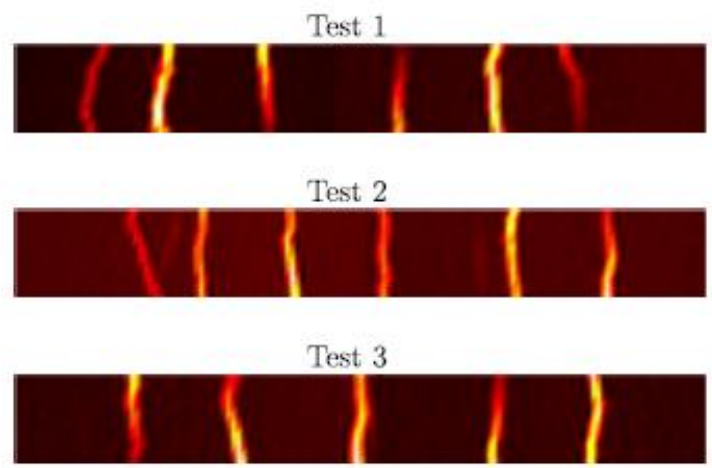

Figure 3: Experimental final cracking pattern - RC ties.

\subsection{Experimental tests for shrinkage and creep}

Experimental measurements of autogenous shrinkage, drying shrinkage, mass loss, basic 
and drying creep are performed on $7 \times 7 \times 28$ $\mathrm{cm}^{3}$ samples. The samples were exposed to an average relative humidity of $45 \% \pm 5$ and an average temperature of $25^{\circ} \mathrm{C} \pm 1$. Autogenous shrinkage was found to be negligible in comparison with drying shrinkage.

\section{MODELLING APPROACH}

The influence of the delayed strains is numerically quantified on the studied specimens. Concrete is considered as mature (mechanical properties of concrete do not evolve). The total concrete strain is calculated according to:

$$
\varepsilon=\varepsilon_{\text {elas }}+\varepsilon_{s h}+\varepsilon_{b c}+\varepsilon_{d c}
$$

Where $\varepsilon_{e l a s} ; \varepsilon_{s h} ; \varepsilon_{b c} ; \varepsilon_{d c}$ are the respective elastic, drying shrinkage, basic creep and drying creep strain.

\subsection{Cracking model for concrete}

The damage model proposed by Mazars [6] has been slightly modified [7]. In this model, a scalar mechanical damage variable is associated to the mechanical degradation process of concrete induced by the development of microcracks. The relationship, between apparent stress $\boldsymbol{\sigma}$, effective stress $\tilde{\boldsymbol{\sigma}}$, damage $D$ (depending also on tensile strength $f_{t}$ ), elastic stiffness tensor $\mathbf{E}$ and other strain $\boldsymbol{\varepsilon}$, reads:

$$
\begin{gathered}
\sigma=(1-D) \tilde{\sigma} \\
\dot{\tilde{\sigma}}=E \dot{\varepsilon}_{\text {elas }}=E\left(\dot{\varepsilon}-\dot{\varepsilon}_{s h}-\dot{\varepsilon}_{b c}-\dot{\varepsilon}_{d c}\right)
\end{gathered}
$$

According to the softening behavior, an energetic regularization [9] prevents of mesh dependency.

\subsection{Bond model}

The approach is based on an explicit 3D meshing and modeling of the interface. The interface area links up the steel rebar, modeled by $1 \mathrm{D}$ truss elements, with concrete around it. Its diameter is taken as equal to the real diameter of the rebar (Fig. 4). The rebarinterface and interface-concrete bonds are considered as perfect with coincident nodes. The Young's modulus and the Poisson's ratio are also taken as equal to the concrete one, in order to guarantee the accurate initial stiffness of the structure.

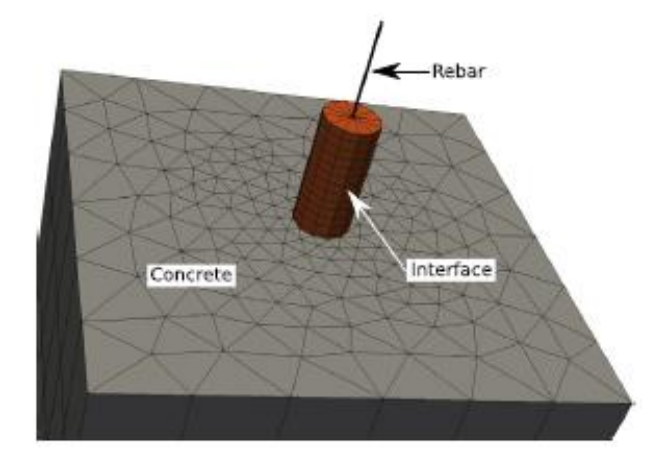

Figure 4: Modelling strategy of the RC tie.

In this communication, the philosophy of the 3D bond model is modified. At a low level of axial tension in the steel rebar, the steelconcrete behavior can be characterized by a chemical bond at the interface. The interface transfers the load from the steel rebar to concrete by shear stresses, without slip between the two materials. Once the cohesion is locally reached, a friction mechanism appears. This step can be easily modeled by a perfect Von Mises criterion:

$$
\sigma_{e q}=K_{1}
$$

However, a ribbed bar exhibits an increase of bond resistance after the initial cohesion. That is mainly due to the local anchorage of the steel ribs into concrete. The stiffness of the interface decreases in this step. Indeed, radial cracks localize at steel ribs and a relative displacement between the two materials can be measured. The cracks later coalesce. The maximum bond resistance is then reached. For larger slip values, the bond strength decreases until a final friction stage. The approaches proposed in the literature do not take into account the local influence of the steel ribs. The bond models rather show a homogenized behavior. The proposed bond model aims to consider the influence of the steel ribs, in order to capture the local concrete degradation at the steel-concrete interface. Obviously, the point is not to explicitly mesh the steel ribs in the numerical simulations. They are implicitly 
considered by a second local criterion in the interface area. Unlike the first overall one (Eq. (4)), a von Mises criterion with softening is locally added at the ribs locations. It is defined as:

$$
\begin{gathered}
\sigma_{e q}=K_{2} \\
d K_{2}=H_{2} d p
\end{gathered}
$$

where $K_{2}$ is the initial local plastic threshold $\left(K_{2} \gg K_{1}\right), H_{2}<0$ is the softening parameter and $\mathrm{p}$ is the cumulative plastic strain. The model can be seen as a periodic field of properties (Fig. 5) and aims to quantify the local mechanisms at the interface.

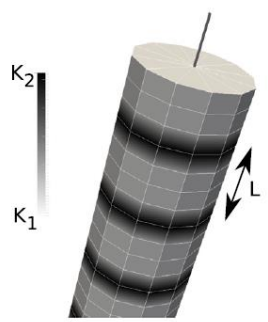

(a)

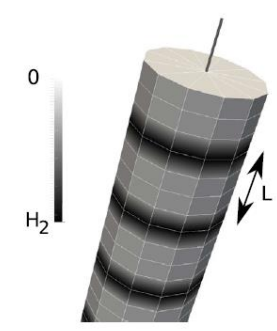

(c)

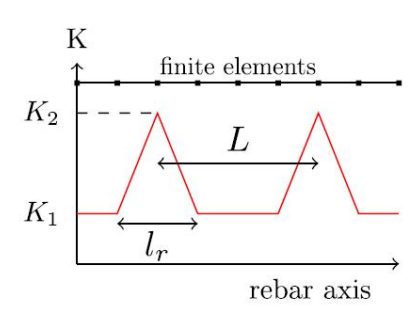

(b)

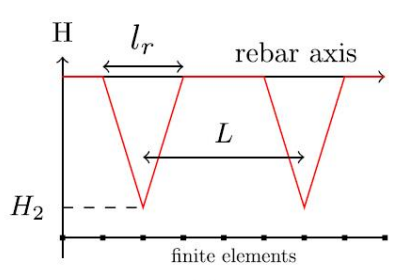

(d)
Figure 5: Periodic field of bond parameters, $L$ : distance between two consecutive ribs.

For the sake of simplicity, each finite element of the interface has the same size along the axis of the interface (Fig. 15a-c). An evolution of the plastic threshold and of the softening parameter is imposed (Fig. 15b-d). An assumption is made that lateral confinement and its effect on bond properties are negligible in our study.

\subsection{Delayed strain model}

The shrinkage strain is a function of time and of the size of the specimen (diffusive phenomenon). In order to focus on reinforcement restraint, the drying shrinkage strain $\varepsilon_{\text {sh_spe, imposed to the reinforced }}$ concrete tie, is obtained according to the following equation (diffusion controlled process) [10]:

$$
\varepsilon_{s h_{-} s p e}\left(\frac{\sqrt{t}}{r_{s p e}}\right)=\varepsilon_{\text {sh_test }}\left(\frac{\sqrt{t}}{r_{\text {test }}}\right)
$$

where $r_{i}$ is the notional size, $i=s p e$ for the RC tie and $i=$ test for the $7 \times 7 \times 28 \mathrm{~cm}^{3}$ sample for which the delayed strains are measured on. The notional size is defined as $2 \times S_{d r} / p_{d r}$, where $S_{d r}$ is the drying surface, and $p_{d r}$ is the drying perimeter $\left(r_{\text {spe }}=5 \mathrm{~cm}, r_{\text {test }}=3.5 \mathrm{~cm}\right)$. Consequently, the shrinkage is supposed uniform in the specimen. This assumption implies that the auto-restraint caused by the drying shrinkage gradient is neglected. The imposed drying shrinkage strain $\varepsilon_{s h \_s p e}$ is presented in Fig. 6. The creep modeling (see [11] for the description of the model) considers basic and drying creep strains in concrete. The drying creep is assumed to be linear and proportional to the drying shrinkage [12]. The basic creep parameters are identified from the experimental creep tests in compression. The specific creep in tension and compression are considered as equal, because of the lack of consensus in the literature [11].

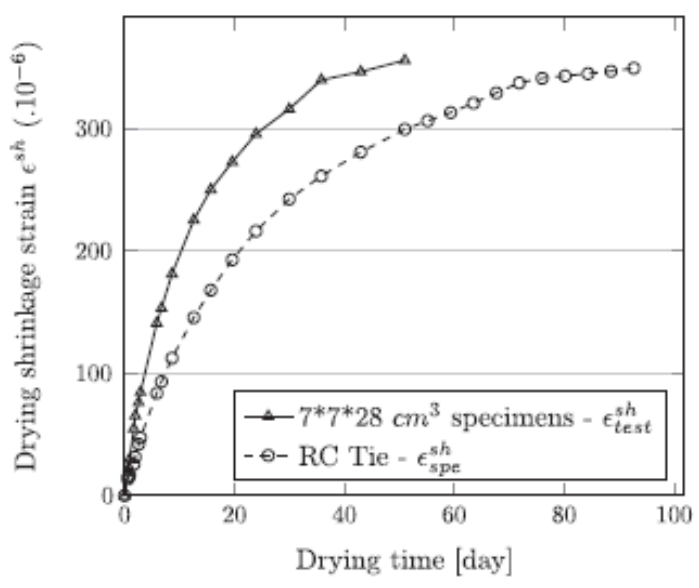

Figure 6: Drying shrinkage strain imposed to the structure.

Specific basic creep strain $\left(\varepsilon_{b c} / \sigma\right)$ after 22

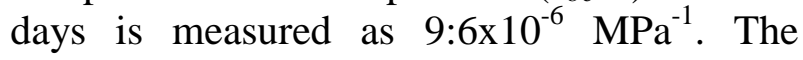
stresses, induced by the drying shrinkage strain, are partially released by the creep 
strains. Hence, creep phenomena have to be automatically considered, to avoid an overestimation of the drying influence.

\section{NUMERICAL SIMULATIONS}

The numerical simulations are carried out with the help of the finite element code Cast3m [8].

\subsection{Validation of the bond model}

The developed bond model is calibrated on the experimental bond tests. Concrete and steel properties are chosen in accordance with the measured values (Table 1). The steel rebar is considered as elastic in this test. The interface area presents a diameter of $12 \mathrm{~mm}$.

The numerical results, obtained with the proposed model, are compared to a "classical" 3D interface one for which a plastic behavior is considered for the interface, following a homogeneous Von Mises criterion with softening along the rebar axis:

$$
\begin{gathered}
\sigma_{e q}=K \\
d K=H d p
\end{gathered}
$$

In the pull-out test, the bond stress with respect to the slip is plotted in the Figure 7 and comparisons between experimental and numerical results are displayed.

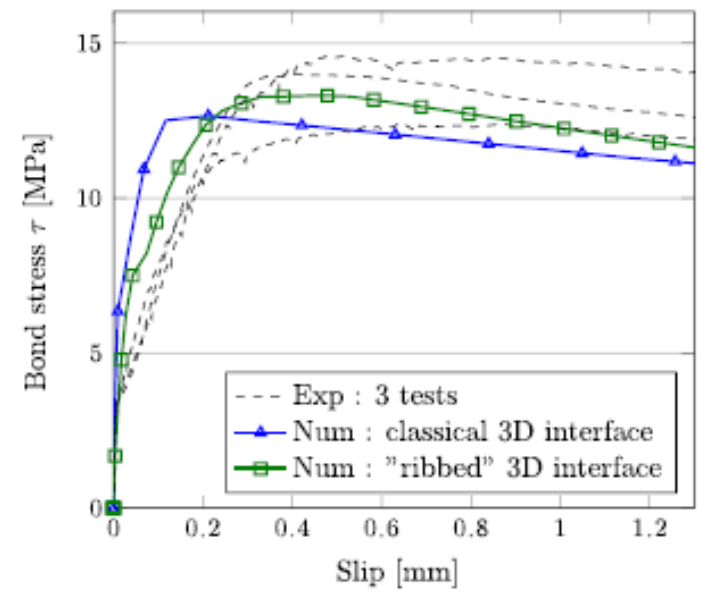

Figure 7: Pull-out tests: effect of the developed model with a "ribbed interface".

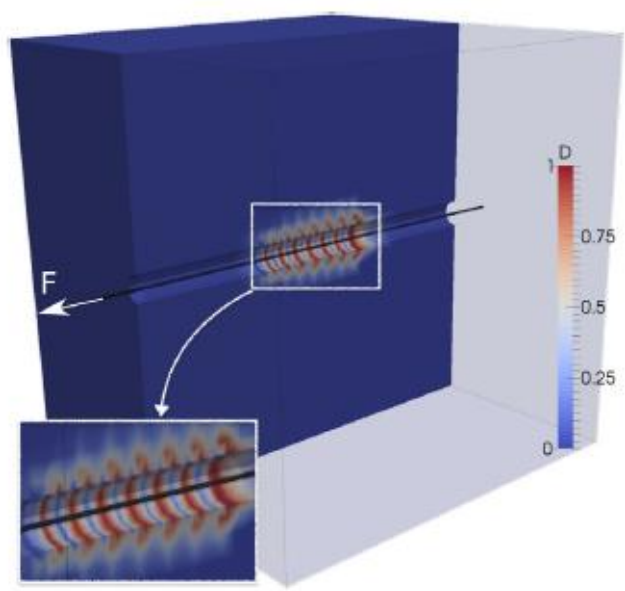

(a)

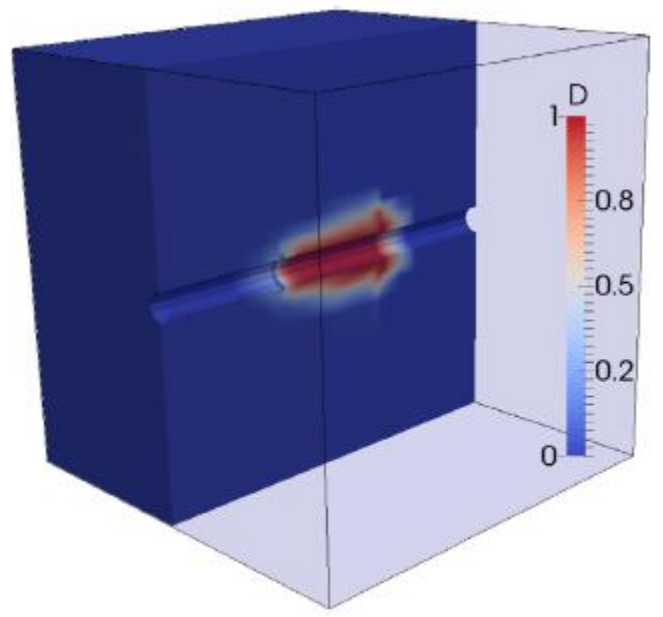

(b)

Figure 8: 3D modeling of pull-out tests, damage field around the interface at $\tau=8 \mathrm{MPa}$ : (a) developed "ribbed" interface and (b) classical 3D approach.

\subsection{Study of the effect of the drying shrinkage}

The effect of drying shrinkage is illustrated on the RC-tie specimen. Ninety days of drying are taken into account (only a quarter is meshed). Fig. 9 shows the damage and axial stress fields after 90 days. Along the interface, it can be observed a slight concrete degradation ( $D$ around 0.3 ) due to the strain incompatibility between concrete and the couple rebar-interface. However, considering a uniform drying shrinkage strain, the rebar restraint induces significant tensile quasiuniform axial stresses in the specimen. The axial stresses are equal to about $0.75 \mathrm{MPa}$ $\left(=1 / 4 f_{t}\right)$. The mechanical response of the 
tension test will be therefore influenced by the "initial" state of stress in the specimen. The stress field is not uniform at the interface, due to the heterogeneities of the bond properties. The threshold $K_{1}$ is reached after 90 days of drying. That explains the stress localizations at the steel ribs, which can favor the crack initiations in the specimen.

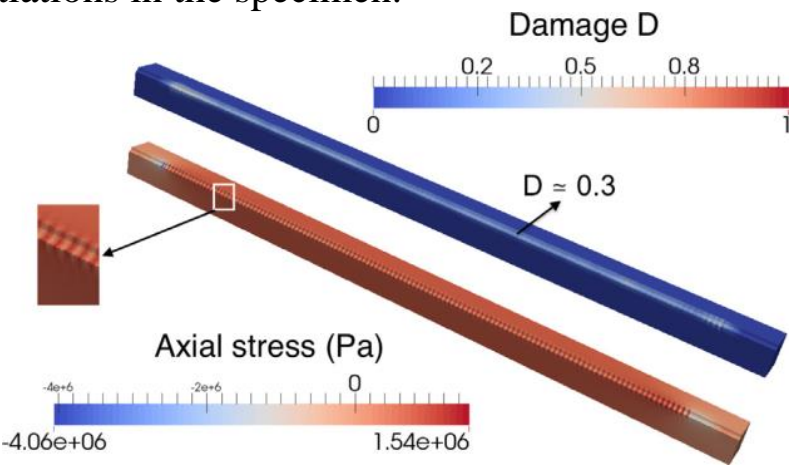

Figure 9: RC tie: stress and damage fields in concrete, after 90 days in drying conditions (quarter of structure) - the steel rebar and the interface are not represented.

The tension test is then numerically carried out. The mechanical response is plotted in Fig. 10. The response is greatly impacted by the drying shrinkage strain in the specimens. The first cracking force decreases by about $30 \%$, in accordance with the initial internal stresses before loading. The first crack establishes the course of the further crack initiations. It is also observed a slight loss of initial stiffness if drying. That is explained by concrete degradation at the steel-concrete interface before loading (Fig. 9).

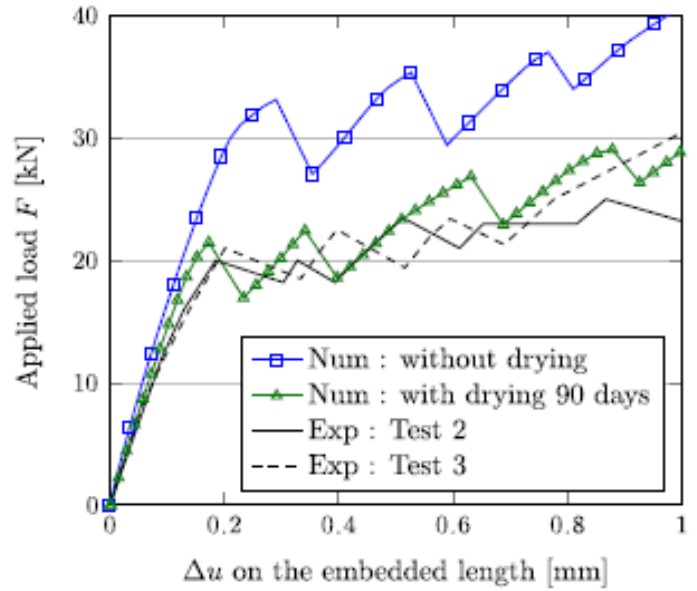

Figure 10: Numerical tension test on RC ties, with or without considering drying (among 90 days).
Finally, the presented results show the importance of considering the delayed strains in structural analysis. It mainly controls the first crack initiation along the specimen. However, the restraint phenomenon is reinforcement-ratio dependent. A specific analysis must be therefore conducted for each specific structure.

In the concern of durability, crack openings obtained experimentally (by DIC at the surface, see $\S 2.2$ ) are compared to predicted one through the sum of crack opening ( $S_{o p}$, Eq. 2). Numerically, crack openings are obtained from the strain field. This method is developed by Matallah et al. [13]. Each simulation is characterized by a new generation of the random field on concrete tensile strength (mean value $f_{t}$, coefficient of variation $5 \%$, correlation length $6 \mathrm{~cm}$ ).

The evolution of $S_{o p}$ is shown in Fig. 11.

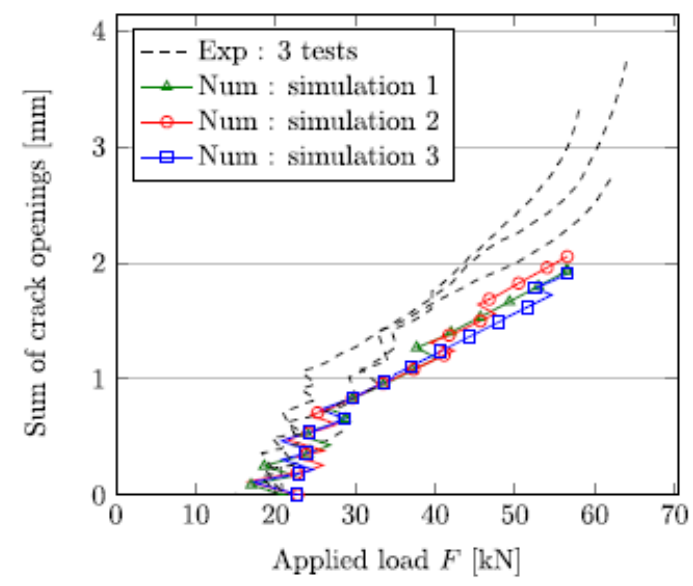

Figure 11: Evolution of $S_{o p}$ during loading, experimental and numerical comparison.

The model reproduces the evolution of Sop, from the first crack initiation (about $20 \mathrm{kN}$ ) until yielding of reinforcement. However, it slightly under-estimates the experimental behavior before yielding $(\mathrm{F}=40-60 \mathrm{kN})$.

\section{CONCLUSIONS}

With the sake of durability, the modeling of reinforced concrete structures is more and more focused on their cracking behavior. The cracking behavior is mainly controlled by the embedded reinforcement and its associated bond behavior. 
A meso-scale reinforcement-concrete interface has been developed in this communication. The associated bond model leads to a fine description of the concrete degradation at the interface: local inclined cracks at the steel ribs, slip between the two materials. Unlike existing approaches, the influence of the steel ribs is implicitly taken into account. The local transfer of internal forces from the steel rebar to concrete is representative of experimental measurements. The bond model can be used for structural applications whose cracking is highly dependent on the behavior of the steelconcrete interface: 4-point bending tests on reinforced concrete beams for example.

Specific attention is devoted to the influence of the concrete delayed strains on the mechanical response of structures. The restraint of drying shrinkage shows a significant effect on the cracking behavior. It has to be taken into account in order to accurately design reinforced concrete structures.

\section{REFERENCES}

[1] Hilaire A, Benboudjema F, Darquennes A, Berthaud Y, Nahas G. 2014. Modeling basic creep in concrete at early-age under compressive and tensile loading. Nucl Eng Des 269:222-30.

[2] Lagier F, Jourdain $X$, De Sa C, Benboudjema F, Colliat J-B. 2011. Numerical strategies for prediction of drying cracks in heterogeneous materials: comparison upon experimental results. Eng Struct 33(3):920-31.

[3] Besnard G, Hild F, Roux S. 2006 Finiteelement displacement fields analysis from digital images: application to Portevin-Le Châtelier bands. Exp Mech 46(6):789803.

[4] RILEM. 1985. Determination of the fracture energy of mortar and concrete by means of three-point bend tests on notched beams. Mater Struct 18(106): 285-90.

[5] Gérard B, Marchand. 2000. J. Influence of cracking on the diffusion properties of cement-based materials. Cem Concr Res 30:37-43.

[6] Mazars J., 1986. A description of micro and macroscale damage of concrete. Engineering Fracture Mechanics 25:729737

[7] Feenstra PH. Computational aspects of biaxial stress in plain and reinforced concrete. PhD thesis. TU Delft; 1993.

[8] Cast3m; 2011. http://www-cast3m.cea.fr/.

[9] Hillerborg A, Modéer M, Petersson P-E. 1976. Analysis of crack formation and crack growth in concrete by means of fracture mechanics and finite elements. Cem Concr Res 6(6):773-81.

[10] Almudaiheem JA, Hansen W. 1987. Effect of specimen size and shape on drying shrinkage of concrete. ACI Mater $J$ 84(2):130-5.

[11] Hilaire A, Benboudjema F, Darquennes A, Berthaud Y, Nahas G. 2014. Modeling basic creep in concrete at early-age under compressive and tensile loading. Nucl Eng Des 269:222-30.

[12] Gamble B, Parrott L. Creep of concrete in compression during drying and wetting.1978. Mag Concr Res 30(104):129-38.

[13] Matallah M, La Borderie C, Maurel O. 2010. A practical method to estimate crack openings in concrete structures. Int $J$ Numer Anal Methods Geomech 34(15):1615-33. 